\title{
Of plants and men
}

SIR - Your review of science in the Low Countries (Nature 7 June, pp.491-510) emphasized the contrasts of administrative style and professional practice between these ostensibly similar countries.

It was, however, the issue of overall similarity that reminded me of an earlier casual observation I had made of a human parallel to the socalled " $-3 / 2$ ecological power law" of plant distribution. In essence, this law in fact, a rule describes the relationship between numbers of a given species in a given area and their combined biomass in such a way that a graph of biomass against distribution density, both on a logarithmic scale, exhibits a linear relationship with a gradient of $-3 / 2$. This observation seems to have originated from Japan $^{1-3}$ and has yet to be properly explained $^{4}$ for plants.

For my part, as an ecological novice, I attempted to explore

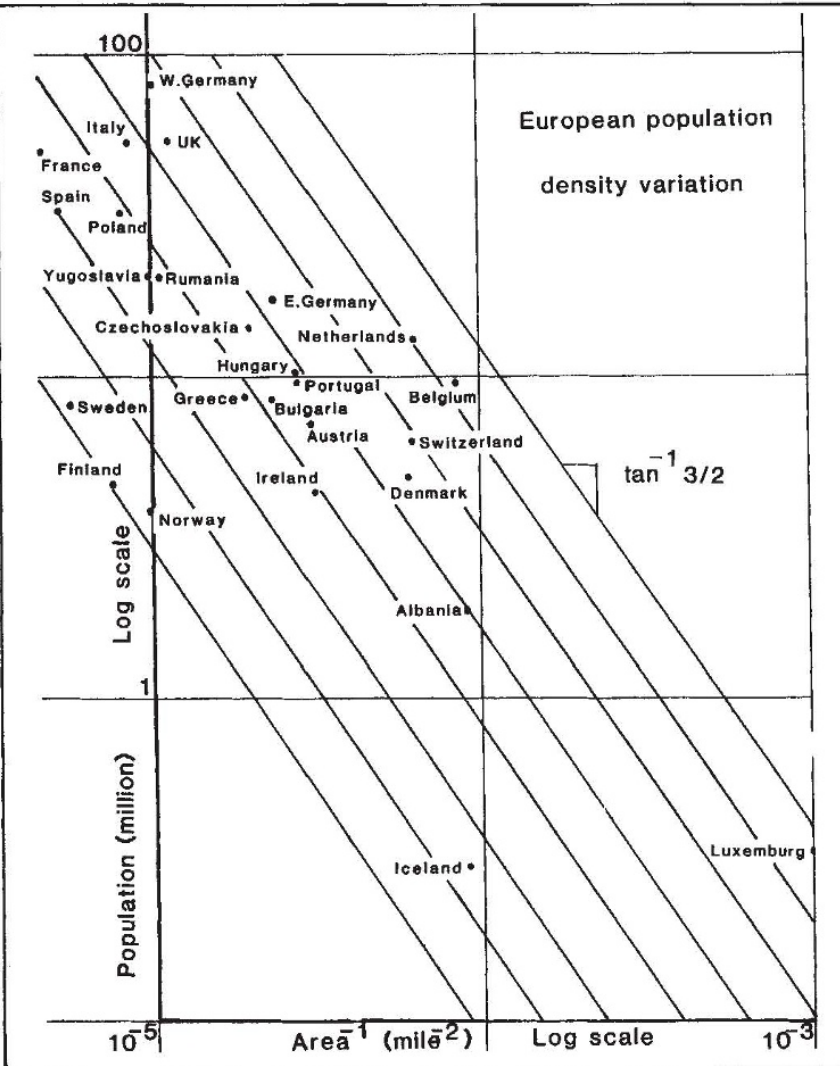

the possibility that the " $-3 / 2$ law" may be represented in faunal distributions as well as plants. Unfortunately, animals are more mobile than plants. Also, the animals for which most distribution data are available to the non-specialist - man - live in civilized communities within which false distributions arise due to activity specializations. Therefore, I decided to test the theory at a national level by "weighing" whole nations, that is, noting the population size, and simultaneously determining their distribution density as 1 nation per national area, that is, $1 \div$ (national area). This removes the anomalies arising from urban centralization, etc.

The outcome of this trivial exercise is most enlightening. On a worldwide basis, the aforementioned log-log graph appears at first sight to be a scatter plot. However, if straight lines with a gradient of $-3 / 2$ are superimposed on it, the nations line up in well ordered fashion, with those which might instinctively be thought to be similar appearing on the same line as one another and distinctly separate from dissimilar nations. A particular case in point is represented by Luxembourg, Belgium and the

Netherlands, the population densities of which, in that order, appear to be similar to the secular development of a group of plants of one species. One could go on to draw attention to certain striking anomalies and to the historical, even anthropological, comments which are thus 